\title{
Temporal Dynamics of Greenhouse Gas Flux of Warm Temperate Deciduous Broad-Leaved Forest Ecosystem Soil in North China
}

\section{Wuxing Wan ( $\square$ wan.wx1972@126.com )}

Hebei Normal University https://orcid.org/0000-0002-6106-517X

\section{Shuai Zhang}

Hebei Normal University

Jie Li

Hebei Normal University

\section{Yiqin Gao}

Hebei Normal University

\section{Meiqi Feng}

Hebei Normal University

Xiaoke Wang

RCEES: Research Centre for Eco-Environmental Sciences Chinese Academy of Sciences

\section{Research}

Keywords: Greenhouse Gas Flux, Warm Temperate Deciduous Broad-Leaved Forest Ecosystem, North China

Posted Date: May 4th, 2021

DOI: https://doi.org/10.21203/rs.3.rs-455687/v1

License: (c) (i) This work is licensed under a Creative Commons Attribution 4.0 International License. Read Full License 


\title{
Temporal Dynamics of Greenhouse Gas Flux of Warm Temperate
}

\author{
Deciduous Broad-Leaved Forest Ecosystem Soil in North China
}

\author{
Wuxing Wan ${ }^{1 *}$, Shuai Zhang ${ }^{1}$, Jie $\mathrm{Li}^{1}$, Yiqin Gao ${ }^{1}$, Meiqi Feng ${ }^{1}$ and
}

Xiaoke Wang ${ }^{2 *}$

\begin{abstract}
Background: According to the WMO's (World Meteorological Organization) Greenhouse Gas Bulletin (2019), the fastest increase atmospheric concentrations of the three main greenhouse gases has been detected in the past 20 years. Researchers have paid more and more attention to the problem of greenhouse gas (GHG) emission. Among the studies, people focus much more on grassland ecosystem than that of forest ecosystem, which has a more important effect on the emission and absorption of greenhouse gases. Estimating the impact of forest ecosystem on greenhouse effect in China is of great significance.
\end{abstract}

Methods: 6 deciduous broad-leaved forest communities with similar elevation, slope orientations and slope gradient in Wuling Mountain National Natural Reserve are employed to conduct the GHG flux study. Five $50 \mathrm{~cm} \times 50 \mathrm{~cm}$ square stainless-steel bases are set in the study site by mechanical spot arrangement method to sample the GHG. The environmental temperature and soil moisture content is measured every sampling time. Static chamber-gas chromatograph method is adopted to examine the greenhouse gas fluxes of $\mathrm{CO}_{2}, \mathrm{CH}_{4}$ and $\mathrm{N}_{2} \mathrm{O}$.

Results and conclusions: The GHG flux of $\mathrm{CO}_{2}, \mathrm{~N}_{2} \mathrm{O}$ and $\mathrm{CH}_{4}$ in the Warm Temperate Deciduous Broad-Leaved Forest Ecosystem has great relationship with environmental temperature and soil water content. GHG flux varies with seasons. Among them, the $\mathrm{CH}_{4}$ flux shows the character of source or sink in different seasons. The other 2 are always the source of GHG flux during the study period. The peak value of $\mathrm{CO}_{2}$ is in summer and that of $\mathrm{N}_{2} \mathrm{O}$ in March. The flux of $\mathrm{CH}_{4}$ shows the feature of source in April and sink in other seasons. The peak value of sink comes in late July. The flux of $\mathrm{CO}_{2}$ has the greatest relationship with the soil temperature $5 \mathrm{~cm}$ below the ground surface and the flux of $\mathrm{N}_{2} \mathrm{O}$ has the greatest relationship with the soil water content. The relationship between $\mathrm{CH}_{4}$ flux and the environmental temperature or the soil water content is complex.

Key words : Greenhouse Gas Flux, Warm Temperate Deciduous Broad-Leaved Forest Ecosystem, North China 


\section{Background}

With the development of global industrialization, greenhouse Gases (GHG) in the atmosphere caused by human activities have increased significantly. There are kinds of gases that can leads to the Greenhouse Effect, among which the three gases that contribute the most to the greenhouse effect include $\mathrm{CO}_{2}, \mathrm{~N}_{2} \mathrm{O}$ and $\mathrm{CH}_{4}$.

$\mathrm{CO}_{2}$ is the most important greenhouse gas except water vapor (IPCC 2000). The 100-year Global Warming Potential (GWP) of $\mathrm{N}_{2} \mathrm{O}$ is 310 times that of $\mathrm{CO}_{2}$, which makes its contribution to the greenhouse effect approximately 6\% (Bouwman et al. 2002; IPCC 1996). The GWP of $\mathrm{CH}_{4}$ is about 25 times that of $\mathrm{CO}_{2}$ (Hansen et al. 1990). Almost one third of global $\mathrm{CH}_{4}$ emissions come from natural sources (Bras et al. 2001), and although its growth rate is lower than that of $\mathrm{CO}_{2}$, it contributes about $20 \%$ to the greenhouse effect caused by greenhouse gases (Sims et al. 2014).

According to the WMO's (World Meteorological Organization) Greenhouse Gas Bulletin (2019), the fastest increase atmospheric concentrations of the three main greenhouse gases has been detected in the past 20 years. The power for the increase of GHG content in atmosphere can be divided into 2 categories: one is the vast use of fossil fuels; the other includes some natural process effects and land-use change (WMO, 2009). Due to the increase of greenhouse gas content in the atmosphere, which exacerbates global climate change, researchers have paid more and more attention to the problem of GHG emission (Apps et al. 1993; Song Changchun et al. 2006; Zhang Lihua, 2005; Nikunja et al. 2018; Marissa et al. 2019).

Forest is the largest carbon pool in terrestrial ecosystems (Sedjo, 1993). It has the widest distribution area, highest productivity and largest biomass accumulation compared to other vegetation types. Any increase or decrease of forest ecosystem carbon storage will affect the atmospheric $\mathrm{CO}_{2}$ concentration. The carbon cycle process of forest ecosystem regulates the dynamics of global terrestrial carbon cycle ( $\mathrm{Li}$ et al. 2003). Among the studies reported on the global estimation of carbon storage and flow, people focus much more on grassland ecosystem than that of forest ecosystem. Forests account for $23.04 \%$ of the land area in China (2021) (http://www.forestry.gov.cn/). It has an important effect on the emission and absorption of greenhouse gases. Estimating the impact of forest ecosystem on greenhouse effect in China is of great theoretical and practical significance for exerting forest ecological benefits effectively and alleviating global warming. In this research, the characteristics of greenhouse gas flux in warm temperate deciduous broad-leaved forest ecosystem are studied by static chamber-gas 
chromatograph method.

\section{Methods and materials}

\section{Plots setting}

49 deciduous broad-leaved standard forest plots with $400 \mathrm{~m}^{2}$ horizontal area has been set in the Wuling Mountain National Reserve in 2011. To make sure that the study results have scientific comparability among the sample plots, 6 deciduous broad-leaved forest communities with similar elevation, slope orientations and slope gradient are employed to conduct the GHG emission study. The 6 chosen plots are all set on the shady slope between $26^{\circ}$ and $30^{\circ}$ gradient at about $1000 \mathrm{~m}$ elevation. Since March 2013, gas samples are collected every three weeks.

\section{Sampling with static chamber}

Static chamber-gas chromatograph method is adopted to monitor the greenhouse gas fluxes of $\mathrm{CO}_{2}, \mathrm{CH}_{4}$ and $\mathrm{N}_{2} \mathrm{O}$. Five $50 \mathrm{~cm} \times 50 \mathrm{~cm}$ square stainless-steel bases are set in the study site by mechanical spot arrangement method. The upper surface of the base is kept horizontal for water sealing. The static chamber is made with transparent acrylic plate. Tube with an inner diameter of $2 \mathrm{~mm}$ and a length of $1.5 \mathrm{~m}$ is used to balance the air pressure inside and outside the static chamber. Digital thermometers and mercurial thermometers are employed to measure the environment temperatures. The water content of the soil is measured. The soil surface temperature is measured by the Smart Sensor AR320 infrared thermometer. JM222U portable digital surface thermometer is used to measure the air temperature and the temperature in the static chamber. Using mercury thermometer to measure soil temperature of $5 \mathrm{~cm}$ beneath the surface. The 0 $20 \mathrm{~cm}$ topsoil near the static chamber is sampled with a soil drill. Collected gas samples is analyzed by Agilent 7890A gas chromatograph within $72 \mathrm{~h}$.

\section{Monitoring implementation}

Gas samples are collected every 3 weeks from March to November in 2013. To make sure that the environment temperature is as close to the daily average as possible, sampling begins at 10:00 am every time. The first sample are collected when the chamber is set simultaneously, and then samples would be collected once every $10 \mathrm{~min}$. During a period of $30 \mathrm{~min}$, a total of 4 gas samples are collected. Samples are collected in $500 \mathrm{ml}$ aluminum - plastic composite air bags. The ambient air temperature, the temperature in the tank and the soil temperature of $5 \mathrm{~cm}$ below the surface are measured 
simultaneously in situ. The $0-20 \mathrm{~cm}$ surface soil are sampled to measure the soil moisture content.

\section{Analyzing for GHG flux}

Flux refers to the physical quantity transported through a unit area interface per unit time. The concentration of the test sample is calculated as follow:

$$
C_{S}=A_{S} \times C_{0} \div A_{0}
$$

$C_{S}$ : Test sample concentration; $C_{0}$ : concentration of standard gas; $A_{s}$ : peak area of test sample; $A_{0}$ : area of standard gas peak.

Greenhouse gas flux is calculated by the following formula:

$$
F=\frac{\rho \cdot V \cdot \Delta C}{A \cdot \Delta t}
$$

Where: $F$ is the flux of measuring gas, $\rho$ is the density of monitoring gas, $\Delta C$ is the variation in the concentration of monitoring gas, $\Delta t$ is the length of monitoring time, $A$ and $V$ are the area at the bottom of the sampling box and the volume of the gas chamber respectively. When the value of $F$ is negative, it indicates that the soil absorbs the greenhouse gas, showing the flux characteristics of "sink". When the value of $F$ is positive, it indicates that the soil emits the greenhouse gas, showing the flux characteristics of "source".

$$
\text { Statistical analysis of data is performed by Excel (16) and SPSS } 22 .
$$

\section{Results and Analysis}

\section{Dynamics of environmental factors in different seasons}

The dynamic process of environmental factors including environmental temperatures and soil water content for the sampling plots in a year are analyzed. (Fig. 1).It can be seen from Fig. 1 that the soil moisture content reached the peak of the year in the first monitoring in March 2013. The average moisture content of the 6 study sample plots is close to $60 \%$. This result should be related to the heavy snow in the winter of 2012. But the soil is still in the frozen state. The average soil temperature 20 $\mathrm{cm}$ below the surface is about $-2^{\circ} \mathrm{C}--3^{\circ} \mathrm{C}$. Soil water cannot exert influence effectively on the ecological process happened in the soil. In the subsequent process, the water content is in the process of decreasing until late May. This is mainly because that the study area is still in the dry season with very little precipitation during this period. However, with the rise of temperature and the absence of leaves for the canopy, the 
ground of the ecosystem is completely open for evaporation from the soil water. As a result, the surface soil can be heated up rapidly and the evapotranspiration intensified. And then, the soil moisture content is in the process of decreasing from March to the end of May.

Environmental factors are: AT: air temperature; ST: surface temperature of the soil; TC: temperature in the chamber; ST-5: soil temperature of $5 \mathrm{~cm}$ below the surface; SWC: soil water content Monitoring time includes: Mar.-L: 3.27-4.1; Apr.-M: 4.13-4.18; May-E: 5.4-5.9; May-L: 5.22-5.27; Jun.-M: 6.8-6.13; Jul.-E: 6.30-7.4; Jul.-L: 7.18-7.23; Aug.-M: 8.11-8.16; Sep.-E: 9.2-9.7; Sep.-L: 9.23-9.28; Oct.-M: 10.11-10.16; Nov.-E: 11.3-11.8.

And: $\mathrm{E}$ for early, $\mathrm{M}$ for middle, $\mathrm{L}$ for late.

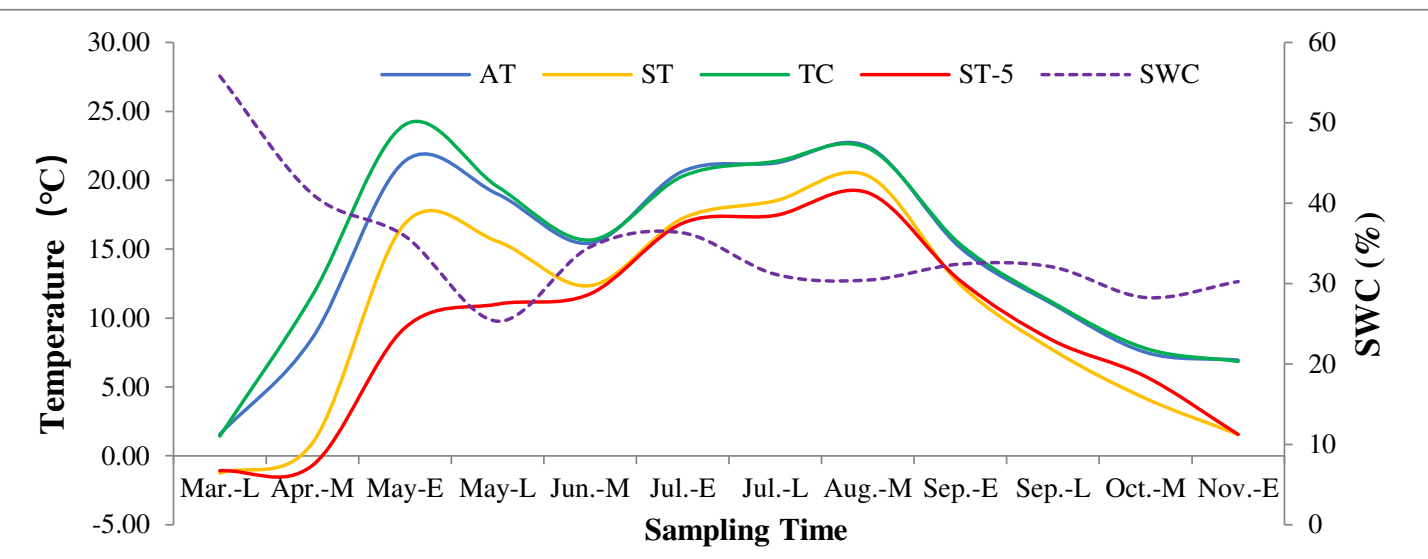

Fig. 1 Variation process of the environmental factors in the year

It gradually enters the rainy season from June in the Wuling Mountain National Reserve. The precipitation increases and the soil water is replenished. From June to October 2013, the soil water content for the monitoring plots is in a relatively stable state. Precipitation in this region is concentrated in June to July and September of 2013, so the soil water content showed two small peaks in the corresponding period.

From the point of dynamic process of the environmental temperature in the year, the average temperature for the 6 plots of the diverse temperature indicators always presents the characteristics that temperature inside the chamber $>$ air temperature $>$ surface temperature $>$ soil $5 \mathrm{~cm}$ temperature. Due to the rapid increase of ambient temperature and the opening of the canopy of the ecosystem, the temperature indices reached their maximum value in May. With the closure of the arbor layer and the beginning of the rainy season, the ambient temperature is getting lower in June. But it reached its peak value again in the middle of August, the hottest days in the summer, which is similar to that in the middle of May.

The warm temperate zone in the continental monsoon climate region is roughly 
between $32^{\circ}-43^{\circ} \mathrm{N}$. Wuling Mountain National Nature Reserve is located at $40^{\circ} 29^{\prime}-$ $40^{\circ} 38^{\prime}$, which belongs to the high latitude area of warm temperate zone. In addition, the altitude of the study sites is relatively high (the average altitude of the 6 plots is about $1000 \mathrm{~m}$ ). It has been in the process of cooling since August. By November, the soil surface temperature is close to $0^{\circ} \mathrm{C}$, reaching the lowest level in this monitoring stage. The temperature in the static chamber is always a little bit higher than the ambient temperature due to the combined effect of illumination, sealing and soil respiration. The temperature in the chamber, the air temperature and the surface temperature are in a similar dynamic process for the whole year (Fig. 1).

Due to the covering effect of the litters over the ground, soil temperature $5 \mathrm{~cm}$ below the surface rise slower than other temperature indices. It didn't clime the peak consistent with the air temperature in May. Whereas, under the combined influence of factors such as air temperature, precipitation, soil temperature $5 \mathrm{~cm}$ below the surface shew a long durable plateau from early May to middle June, raised from late June and peaked in August. Then, it continued to reduce together with the dropping of the air temperature.

Taking the environmental temperature and soil moisture into account comprehensively, they entered a rapid changing process from the beginning of environmental warming and soil freeze-thaw in spring. From June to August, summer and rainy season are in this region. After entering this stage, environmental temperature and soil hydrology are in a stable and slowly rising period. The air temperature is the highest in August, and rainfall is also the most concentrated simultaneously. After September, the environmental temperature and soil moisture continued to decrease in the relatively dry autumn and winter in this region.

\section{Temporal variation characteristics of greenhouse gas flux}

\section{Diurnal dynamic process}

Due to the variation of solar radiation intensity and the air temperature in the daytime from morning to night, as the main influencing factors to the greenhouse gas flux, the soil temperature and soil moisture varies with the time through the day. The activity of the roots of the plants, soil microbials and soil animals will fluctuate with time. The rate of greenhouse gas emissions or deposit will be diverse in different time. The variation process of greenhouse gas flux from morning to night is monitored per hour on April, July and September respectively. The result is employed to estimate the greenhouse gas flux in warm temperate deciduous broad-leaved forest ecosystems (Fig. 


\section{(1) Process of $\mathrm{CO}_{2}$ flux}

The results show that $\mathrm{CO}_{2}$ is the source of greenhouse gas flux in warm temperate deciduous broad-leaved forests in all seasons. In the hourly diurnal variation monitoring, the emission level in July is the highest, while that in April is the lowest, indicating that

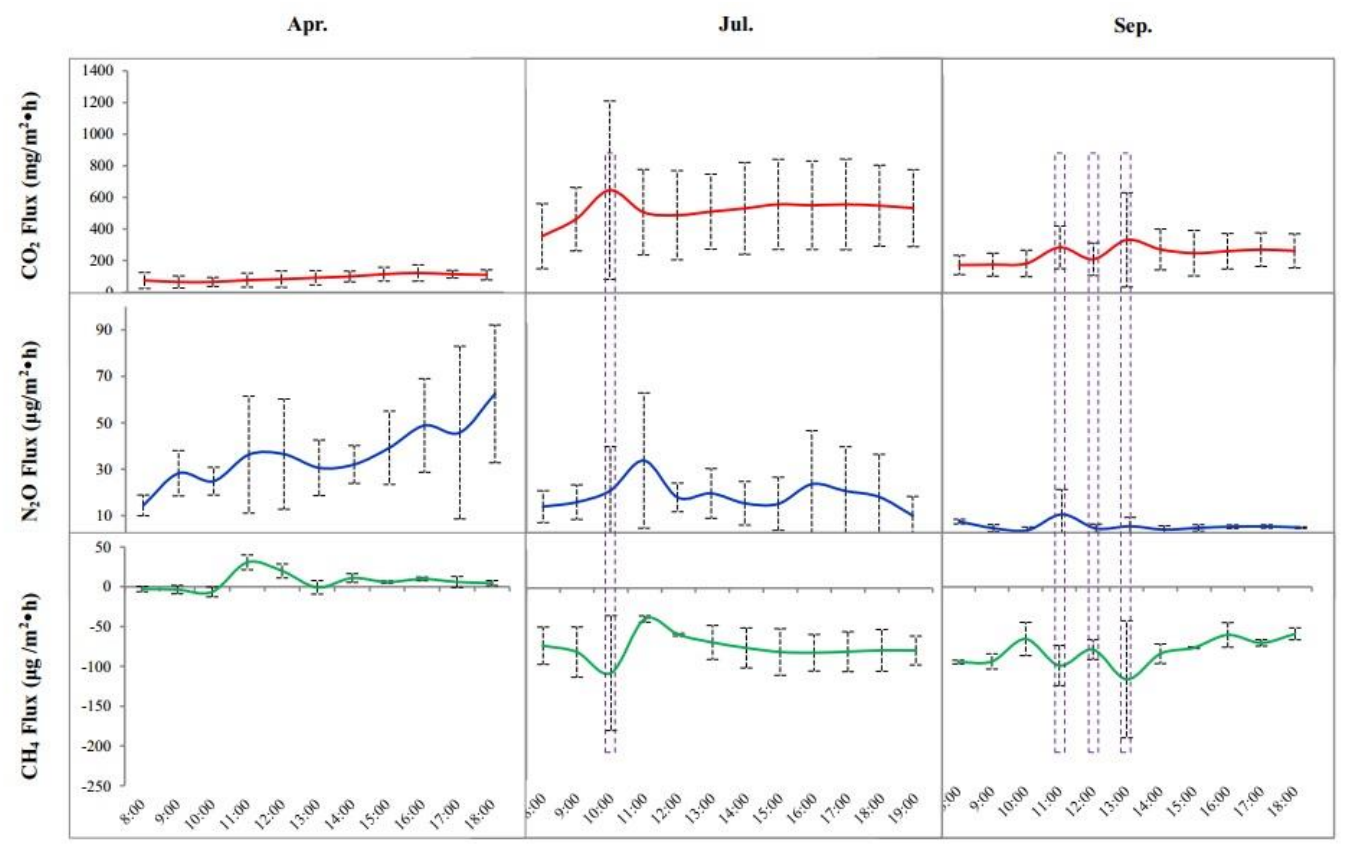

Fig. 2 Dynamic process of GHGs flux rate during a day in different seasons

the emission level of $\mathrm{CO}_{2}$ in summer is higher than that in other seasons. Basing on the process of diurnal variation, the flux of $\mathrm{CO}_{2}$ in April has been rising steadily at a low level from 8 o'clock in the morning, reaching the peak at 16 o'clock in the afternoon and then decreased. In July, the peak value reached at 10 o'clock and had no significant change until 19 o'clock. In September, there are two peaks at 11 o'clock and 13 o'clock. Basing on the monitored $\mathrm{CO}_{2}$ diurnal emission process in three seasons, the daytime $\mathrm{CO}_{2}$ emission showed a tendency of continuous increase on the whole.

\section{(2) Process of $\mathrm{N}_{2} \mathrm{O}$ flux}

The flux process in a year of $\mathrm{N}_{2} \mathrm{O}$ are different from that of $\mathrm{CO}_{2}$, with the highest emission level occurring in April rather than July in summer. In the research plots, April is the soil freeze-thaw season. Studies have shown that a large amount of $\mathrm{N}_{2} \mathrm{O}$ is discharged from the soil in the period of soil freeze-thaw (Li et al. 1999). In April, the diurnal flux variation showed that the emission level is high and continued to rise during the day from morning to night. The diurnal variation pattern of July is different from 
that of April. In this season, the total daytime emission level is relatively stable, but there are two peaks at 110'clock and 16 o'clock. $\mathrm{N}_{2} \mathrm{O}$ emissions in September are significantly lower than in April and July. Diurnal flux is stabilizing at lower level except for a peak at 11 o'clock.

\section{(3) Process of $\mathrm{CH}_{4}$ flux}

The diurnal variation of $\mathrm{CH}_{4}$ flux is relatively complex. The monitoring results show that the diurnal $\mathrm{CH}_{4}$ flux in April generally presents the characteristics of source, with an obvious peak at 11 o'clock and another lower peak at 14 o'clock. The flux at the rest of the monitoring time is relatively stable. And in July and September, it performed as a sink. From the diurnal variation characteristics of sink, the peak for $\mathrm{CH}_{4}$ absorption appeared simultaneously with the peak for $\mathrm{CO}_{2}$ emission. It indicates that there could be a direct relationship between $\mathrm{CH}_{4}$ and $\mathrm{CO}_{2}$ in the process of source-sink flux.

\section{Seasonal dynamics of GHG}

\section{(1) $\mathrm{CO}_{2}$ flux in different seasons}

According to the diurnal process and seasonal variations of $\mathrm{CO}_{2}$ flux, the dynamic processes in different seasons of the 6 plots are estimated (Fig. 3). The results show that the $\mathrm{CO}_{2}$ emission process in a year presents a single peak curve in general and reached its peak in mid-August. There are differences in $\mathrm{CO}_{2}$ flux among different plots. The total emission level of plot 1 and plot 6 is higher, while plot 4 is the lowest. Many studies have shown that the $\mathrm{CO}_{2}$ flux has the highest emission rate in summer, followed by that in spring and autumn, and the lowest emission rate in winter (Wang et al. 2004), which is consistent with the conclusion of this study.

The characteristic of the $\mathrm{CO}_{2}$ flux dynamic is mainly caused by seasonal changes in temperature and soil moisture content. In summer, higher soil temperature and water content enhance microbial activity and root respiration. Total soil respiration is promoted ( $\mathrm{Li}$ et al. 1987). The $\mathrm{CO}_{2}$ emission rate in rainy season is much higher than that in dry season (Chen et al. 2004). There has been another study on the greenhouse gas emission flux and dynamics of forest soil in the West Mountain area of Beijing (Sun et al. 1999). The result show that when the soil temperature in winter is below zero, forest soil acted as a sink for $\mathrm{CO}_{2}$. Whereas, our study did not find that the same result of a sink for $\mathrm{CO}_{2}$ in winter, which is different from the research conducted in West Mountain of Beijing. The two study regions belong to a similar climatic zone and the difference in latitude between the two places is about $0.6^{\circ}$ only. More study is needed 
to uncover the reason for the different characteristics of $\mathrm{CO}_{2}$ flux in winter between the 2 places.

The dynamic process of $\mathrm{N}_{2} \mathrm{O}$ flux in a year is different from that of $\mathrm{CO}_{2}$, which shows high emissions in 5 of the 6 plots at the end of March (Fig. 4). The remaining one of plot 1 claimed its $\mathrm{N}_{2} \mathrm{O}$ emission peak in April. Two other small peaks occurred

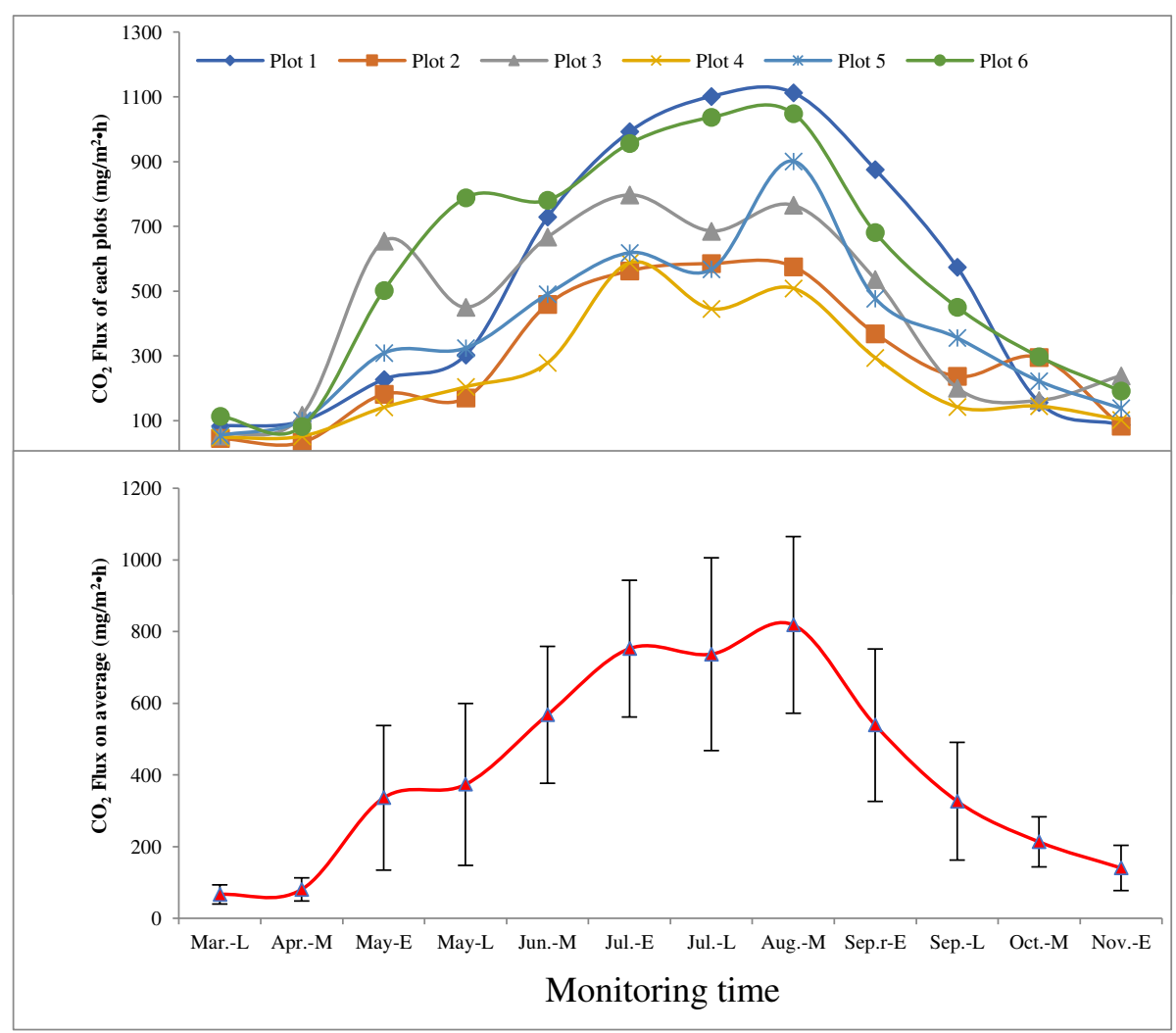

Fig. 3 Dynamic process of $\mathrm{CO}_{2}$ flux rate in different seasons

in early July and mid-August. According to the average emission level of the 6 plots overall, the $\mathrm{N}_{2} \mathrm{O}$ emission level is the highest in late March at an average emission rate close to $100 \mu \mathrm{g} / \mathrm{m}^{2} \cdot \mathrm{h}$. The peak in mid-July is close to $50 \mu \mathrm{g} / \mathrm{m}^{2} \cdot \mathrm{h}$, and the other small peak appeared in mid-August is close to $20 \mu \mathrm{g} / \mathrm{m}^{2} \cdot \mathrm{h}$.

The production process of soil $\mathrm{N}_{2} \mathrm{O}$ is very complex and is affected by many environmental factors ( $\mathrm{Li}$ et al. 1999), among which the soil temperature, soil water content and precipitation before sampling have the most significant effects on the monitoring result of soil $\mathrm{N}_{2} \mathrm{O}$ flux. In addition, the difference of soil $\mathrm{C}$ and $\mathrm{N}$ content and various environmental factors that have an effect on metabolic processes such as respiration, nitrification and denitrification all have an impact on soil $\mathrm{N}_{2} \mathrm{O}$ flux. 
Therefore, the characteristics of $\mathrm{N}_{2} \mathrm{O}$ flux have significant spatial and temporal specificity.

Some studies have shown that $\mathrm{N}_{2} \mathrm{O}$ emissions are the highest in summer, followed by spring and autumn, and the lowest or even negative in winter (Sun et al. 2001; Teepe et al. 2004). In this study, the peak of soil $\mathrm{N}_{2} \mathrm{O}$ emission in the warm temperate deciduous broad-leaved forest occurs in April, which is different from the research

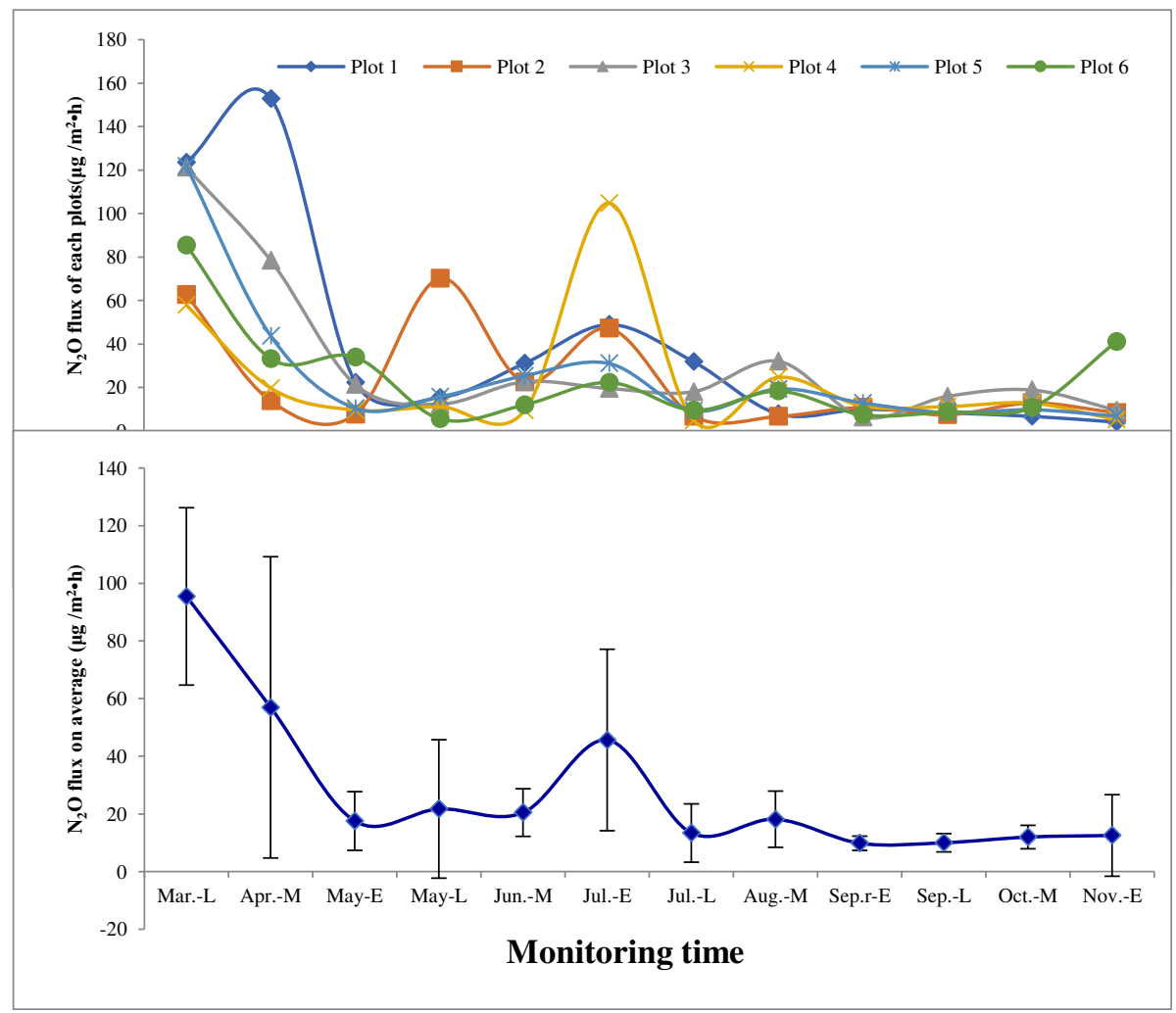

Fig. 4 Dynamic process of $\mathrm{N}_{2} \mathrm{O}$ flux rate in different seasons

results of Sun Xiangyang (2001) and Teepe (2004). The reasons for the difference among the studies need further revealing.

\section{(3) $\mathrm{CH}_{4}$ flux in in different seasons}

It is found that $\mathrm{CH}_{4}$ flux in the warm temperate deciduous broad-leaved forest ecosystem had seasonal variation between source and sink. The $\mathrm{CH}_{4}$ flux for 5 of the 6 monitoring plots, except plot 2 , showed the characteristics of source in mid-April. The overall average level of $\mathrm{CH}_{4}$ flux on this time of each ecosystem also showed the characteristics of source (Fig. 5). In other monitoring periods in the year, the soil of the 
On the average $\mathrm{CH}_{4}$ flux level of the 6 study plots in a year, as a function of sink,

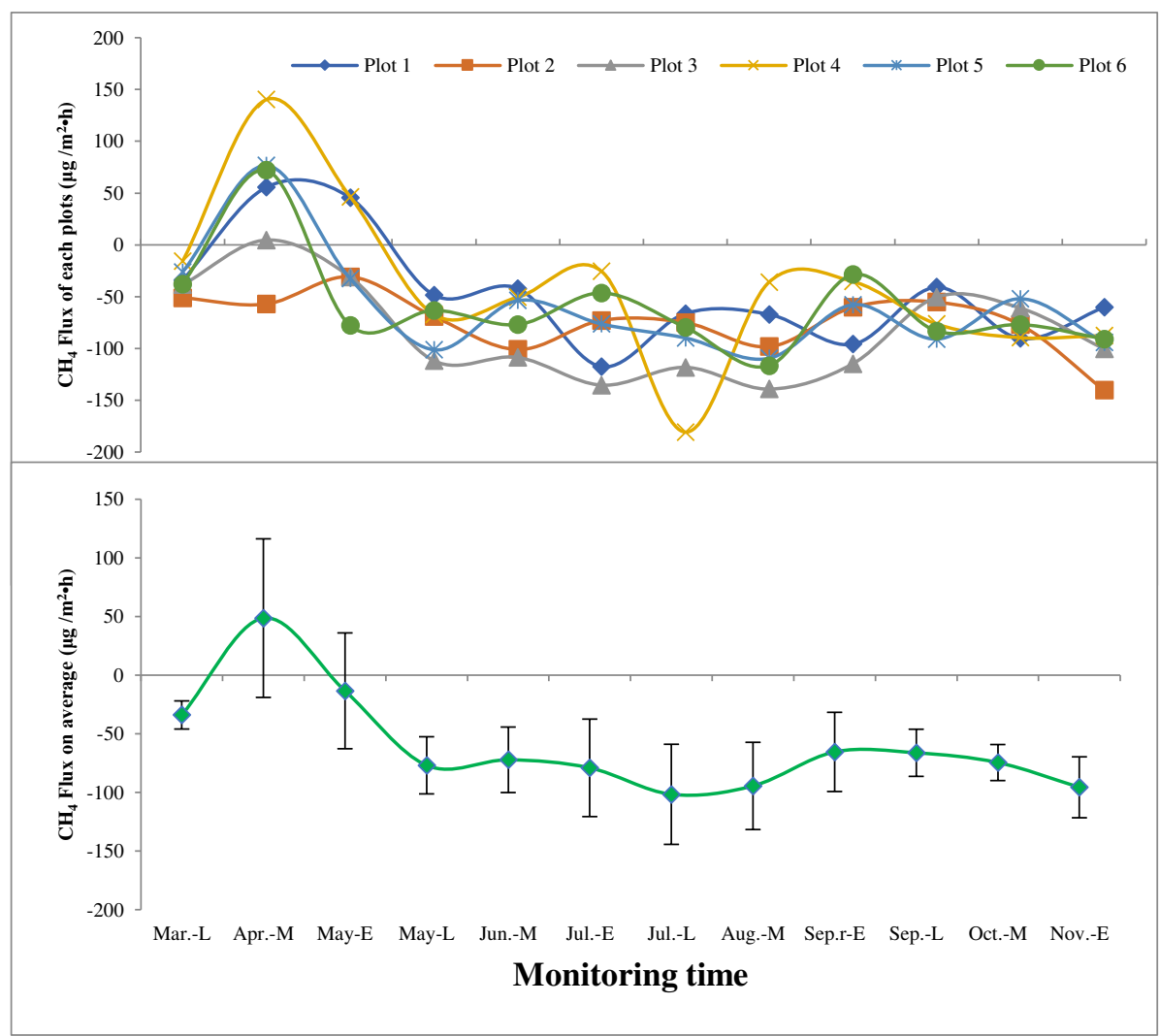

Fig. 5 Dynamic process of $\mathrm{CH}_{4}$ flux rate in different seasons

the highest $\mathrm{CH}_{4}$ absorption of forest soil occurred from late July to mid-August. Soil temperature, soil moisture content, soil physical and chemical properties and changes in land use patterns will affect the characteristics of soil CH4 flux (Li et al. 1999).

\section{Conclusions}

1) Soil moisture reached its peak in March 2013 and showed a downward trend until the end of May. After June, it entered the rainy season, and the soil moisture stabilized at about $30 \%$. The ambient temperature always presents the relationship that: temperature inside the chamber $>$ air temperature $>$ surface temperature $>$ soil temperature $5 \mathrm{~cm}$ below the surface. Ambient temperature has two peaks in May and August. Since August, it has been in the process of cooling, and by November, the surface temperature has been close to $0^{\circ} \mathrm{C}$.

2) There were significant seasonal differences in the diurnal variation of GHG fluxes. The maximum value of $\mathrm{CO}_{2}$ was in summer, and the peak value of daily flux appeared at 10:00 am. It's flux level in autumn was lower than that in summer, and two 
peaks appeared at 11:00 and 13:00. The emission level of $\mathrm{N}_{2} \mathrm{O}$ was the highest and rose in April. Then the emission level of $\mathrm{N}_{2} \mathrm{O}$ was higher in summer than in autumn. The peak value in summer was at 11:00 and 16:00, and the peak value in autumn was at 11:00 in the morning. In April, $\mathrm{CH}_{4}$ flux shows the characteristics of source overall. In summer and autumn, then is a sink. And the peak of sink occurs at the same time as $\mathrm{CO}_{2}$.

3) The seasonal dynamic process of $\mathrm{CO}_{2}$ flux is a unimodal curve and the peak is in summer. The $\mathrm{N}_{2} \mathrm{O}$ flux peaked in March, and then two peaks appeared in early July and mid-August, and the peak value in July was higher than that in August. $\mathrm{CH}_{4}$ flux showed as a source in April and a sink in other seasons. The peak of absorption appeared in late July.

4) The seasonal dynamic of $\mathrm{CO}_{2}$ flux is consistent with the ambient temperature, especially the soil temperature $5 \mathrm{~cm}$ below the surface. The seasonal dynamic of $\mathrm{N}_{2} \mathrm{O}$ flux is consistent with the topsoil water content, and the source-sink capacity of $\mathrm{CH}_{4}$ flux is opposite to the soil moisture content. The dynamic relationship between $\mathrm{CH}_{4}$ and $\mathrm{N}_{2} \mathrm{O}$ fluxes and temperature is complex.

\section{Acknowledgements}

We thank the support of Wuling Mountain National Nature Reserve Administration. Traffic problem smoothly resolved. The filed study could not be conducted without the help from Dongyi Li, Xuequan Feng, Jianguo Sun, Yafei Xiang, Jian'gang Guo and Zhifu Wu.

\section{Authors' contributions}

Wuxing wan designed the study and developed the whole process, including all the sampling work, data monitoring and analysis of the result. Xiaoke Wang provided comprehensive guidance to the design, implementation and data analysis of the study. Shuai Zhang and Jie Li collected and prepared the data. Yiqin Gao and Meiqi Feng analyzed the data and draw the diagram. All authors contributed and approved the final manuscript.

\section{Funding}

We acknowledge funding by Science and Technology Project of Hebei Education Department (ZD2015091) and project of Natural Science Foundation of Hebei Province (C2017205152).

\section{Availability of data and materials}

The datasets used and/or analyzed during the current study are available from the 
331

332

333

334

335

336

337

338

339

340

341

342

343

344

345

346

347

348

349

350

351

352

353

354

355

356

357

358

359

360

361

362

363

364

corresponding author on reasonable request.

\section{Declarations}

Ethics approval and consent to participate

Not applicable.

\section{Consent for publication}

Not applicable.

\section{Competing interests}

The authors declare that they have no competing interests.

\section{Author details}

${ }^{1}$ College of Life Sciences, Hebei Normal University, Shijiazhuang 050024, China

${ }^{2}$ State Key Laboratory of Urban and Regional Ecology, Research Center for Eco-

Environmental Sciences, Chinese Academy of Sciences, Beijing 100085, China

\section{References}

Apps M. J., Kurz W.A., Luxmoore R.J. Boreal forests and tundra [J]. Water, Air, and Soil Pollution, 1993,70(1-4):39-53.

Bouwman A. F., Boumans L. J. M., Batjes N. H. Emissions of $\mathrm{N}_{2} \mathrm{O}$ and $\mathrm{NO}$ from fertilized fields: Summary of available measurement data [J]. Global Biogeochemical Cycles, 2002,16(4):6-16-13.

Bras O., Guillou C., Reniero F. The global methane cycle: isotope sand mixing ratios, sources and sinks[J]. Isotopes in environmental and health studies, 2001,37(4):257-379.

Chen P. Q. Carbon Cycle in Earth System [M]. China Science Press, Beijing, 2004:266-268.

Hansen J, Fung I, Lacis A, et al. Global climate changes as forecast by Goddard Institute for Space Studies three-dimensional model[J]. Journal of Geophysical Research: Atmospheres (19842012), 1988,93(D8):9341-9364.

International Panel on Climate Change, Working Group 1 Third Assessment Report. Cambridge Univ. Press, Cambridge, MA, 2001.

IPCC. The Revised 1996 IPCC Guidelines for National Greenhouse Gas Inventories, Reference Manual. UK Meteorological Office, Bracknell, 1997.

$\mathrm{Li}$ G, Jiang R, Fu Y. Phytomass and the seasonal dynamics of an alpine meadow in Tianzhu[C]//Proceedings of the International Symposium on Grassland Vegetation. Hohhot, PR China. 1987:407-412.

Li Haitao, Shen Wenqing, Liu Qijing, Yu Guirui. On the Study of Carbon Cycle in Wetland Ecosystems[J]. Jiangxi Science, 2003,21(3):160-167. 
Li Yu 'e, Lin Erda. Progress in Study on Methane Uptake by Aerobic Soil[J]. Advance in Earth Sciences. 1999,14(6):613-618.

Marissa Malahayati, Toshihiko Masui. The impact of greenhouse gas mitigation policy for land use and the forestry sector in Indonesia: Applying the computable general equilibrium model[J]. Forest Policy and Economics, 2019,(109), 102003.

Nikunja Mohan Modak a, Debabrata Kumar Ghosh b, Shibaji Panda c, Shib Sankar Sana d. Managing greenhouse gas emission cost and pricing policies in a two-echelon supply chain. CIRP Journal of Manufacturing Science and Technology, 2018,(20):1-11.

Sedjo R A. The carbon cycle and global forest ecosystem[J]. Water, Air, and Soil Pollution, 1993,70(1-4):295-307.

Sims R, Schaeffer R, Creutzig F, et al. Transport. In: Climate Change 2014: Mitigation of Climate Change. Contribution of Working Group III to the Fifth Assessment Report of the Intergovernmental Panel on Climate Change[M]. 2014.

SONG Chang-chun, ZHANG Li-hua, WANG Yi-yong, ZHAO Zhi-chun. Annual Dynamics of $\mathrm{CO}_{2}$, $\mathrm{CH}_{4}, \mathrm{~N}_{2} \mathrm{O}$ Emissions from Freshwater Marshes and Affected by Nitrogen Fertilization[J]. Environmental Science, 2006,27(12):2369-2375.

Sun xiangyang, Xu huacheng. Emission flux of nitrous oxide from forest soil in Bejing[J]. Scientia Silvae Sinicae. 2001,37(5):57-63.

Sun Xiangyang. A Study on Forest Soil $\mathrm{CO}_{2}, \mathrm{~N}_{2} \mathrm{O}$ and $\mathrm{CH}_{4}$ Emission Flux and Dynamics in Xishan Area, Beijing[D]. 1999.

Teepe R, Ludwig B. Variability of $\mathrm{CO} 2$ and $\mathrm{N} 2 \mathrm{O}$ emissions during freeze thaw cycles: Results of model experiments on undisturbed forest soil cores[J].Journal of Plant Nutrition and Soil Science. 2004,16(7):153-159.

Wang G, Du R, Kong Q, et al. Experimental study on soil respiration of temperate grassland in China[J]. Chinese Science Bulletin. 2004,49(6):642-646.

WMO Greenhouse Gas Bulletin (GHG Bulletin) - No. 15: The State of Greenhouse Gases in the Atmosphere Based on Global Observations through 2018, World Meteorological Organization (WMO), 2019.

WMO Greenhouse Gas Bulletin (GHG Bulletin) - No. 5: The State of Greenhouse Gases in the Atmosphere Using Global Observations through 2008, World Meteorological Organization (WMO), 2009.

ZHANG Lihua, SONG Changchun, WANG Dexuan. $\mathrm{CO}_{2}, \mathrm{CH}_{4}$ and $\mathrm{N}_{2} \mathrm{O}$ emissions to the atmosphere upon nitrogen addition in the swamp wetland[J]. Acta Scientiae Circumstantiae. 2005,25(8):1112-1118. 
Figures

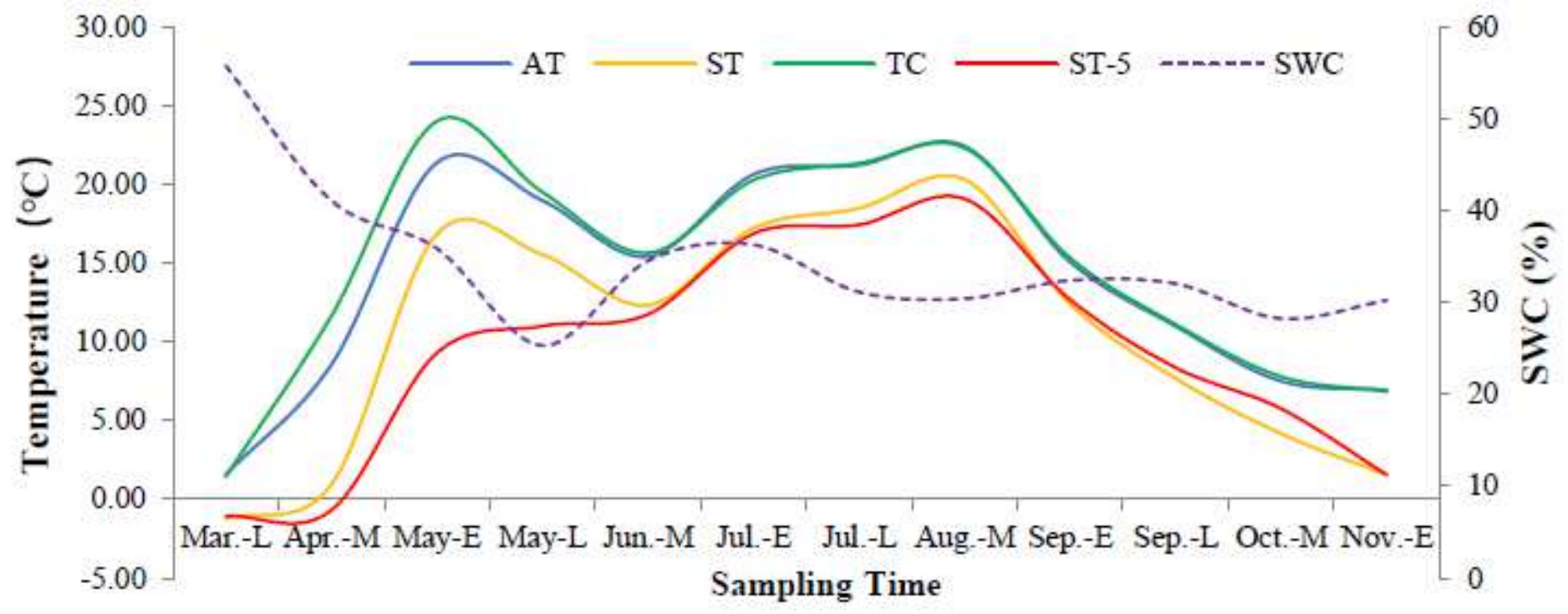

Figure 1

Variation process of the environmental factors in the year

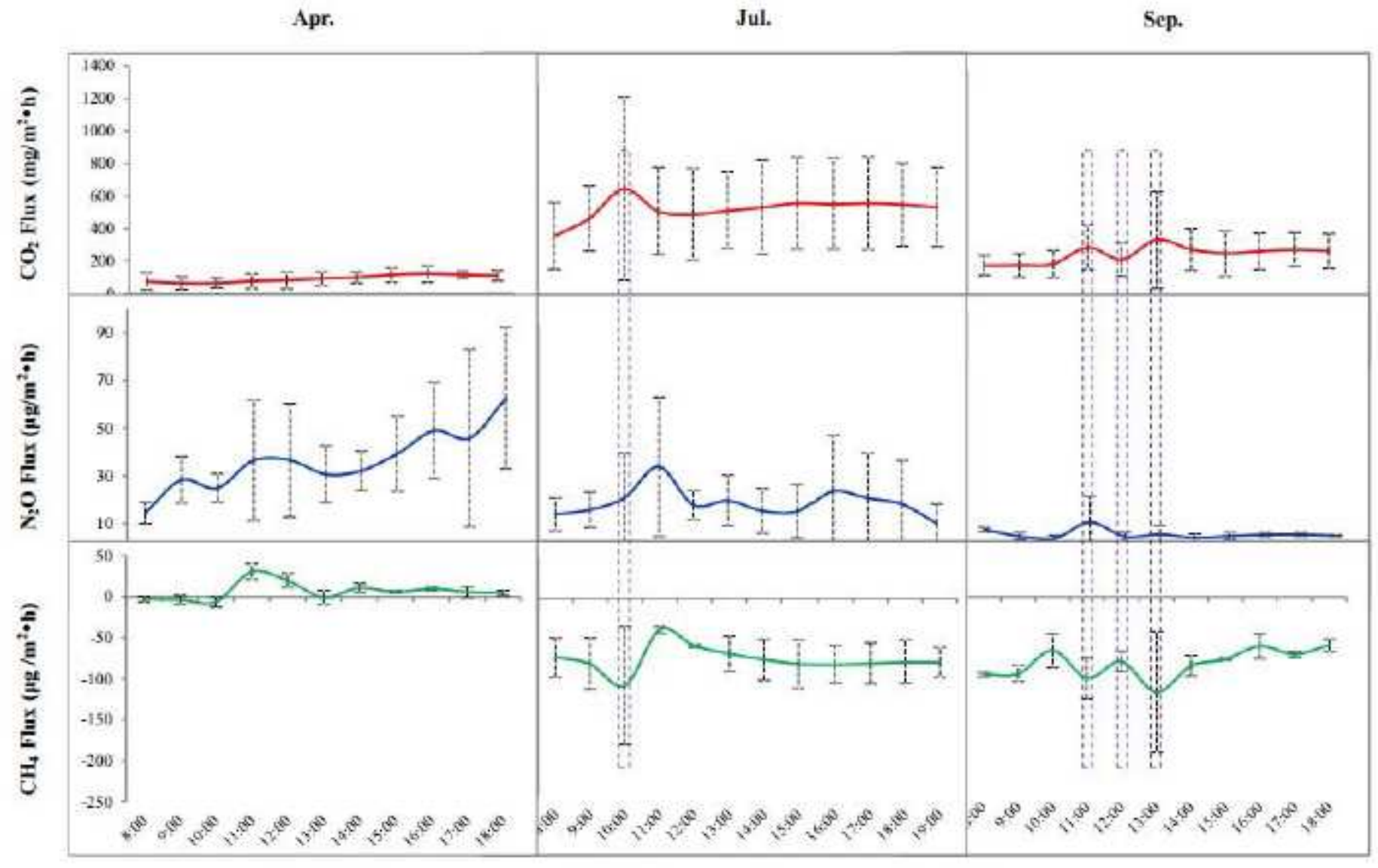

Figure 2 
Dynamic process of GHGs flux rate during a day in different seasons

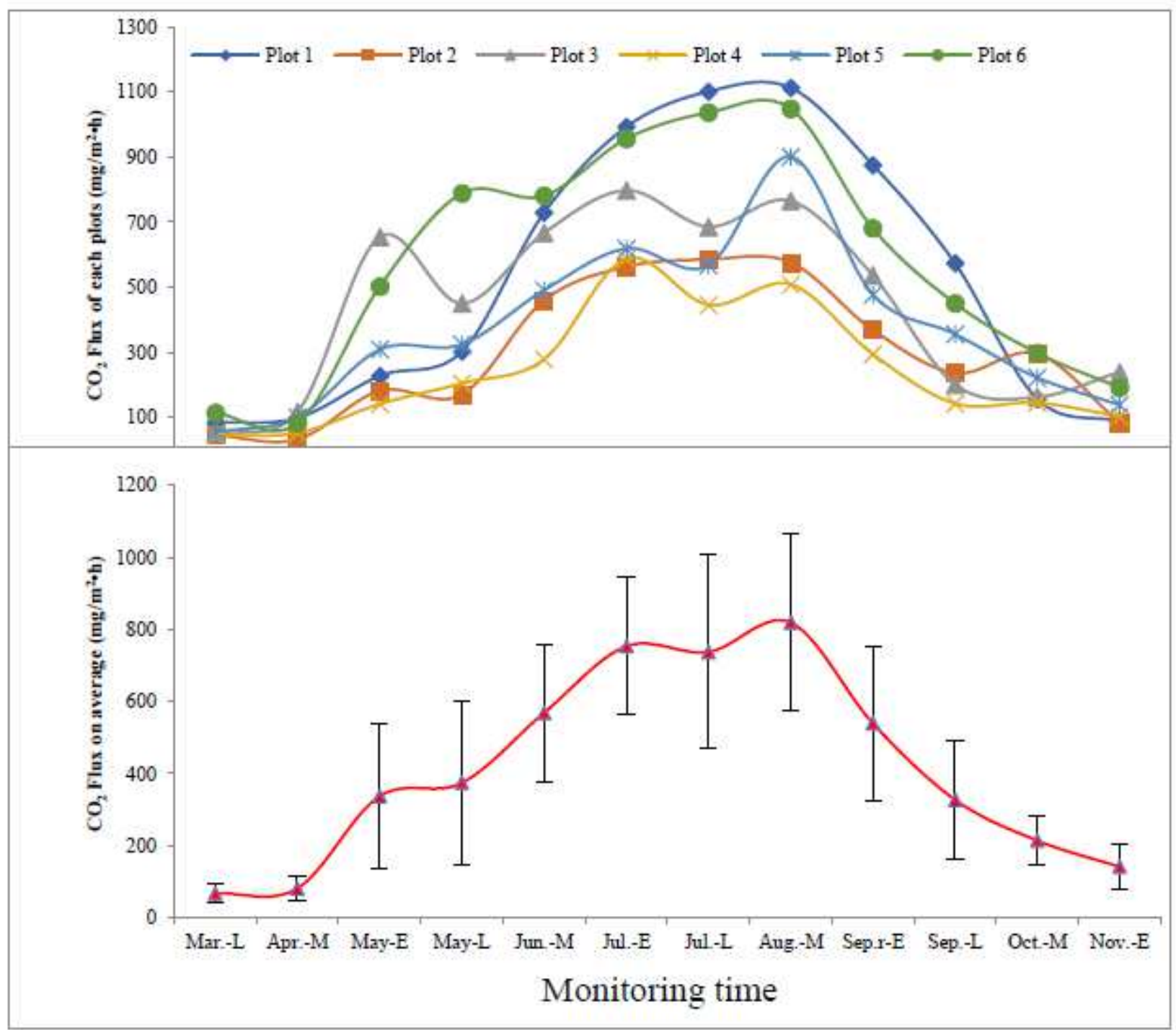

\section{Figure 3}

Dynamic process of $\mathrm{CO} 2$ flux rate in different seasons 


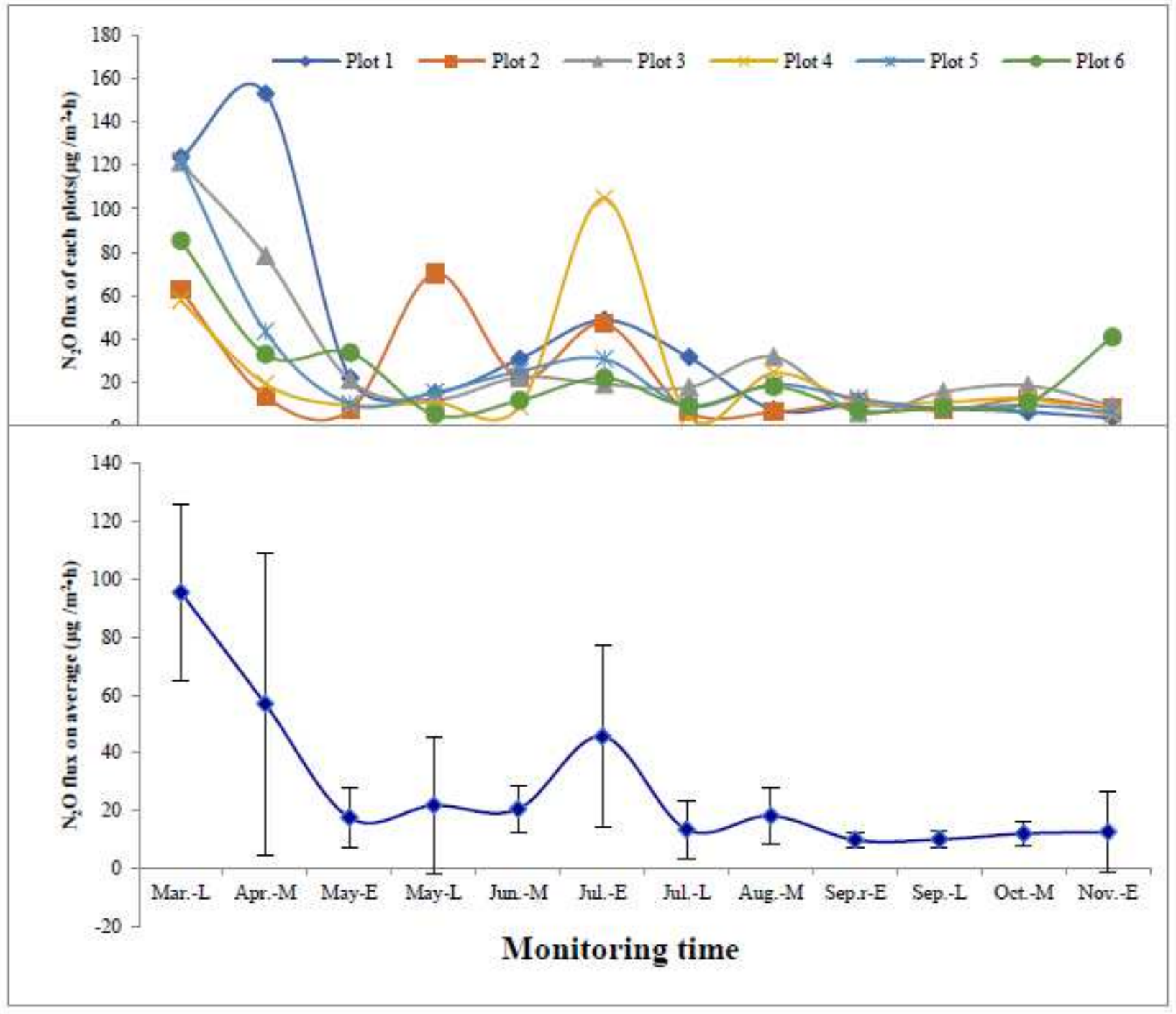

Figure 4

Dynamic process of $\mathrm{N} 2 \mathrm{O}$ flux rate in different seasons 


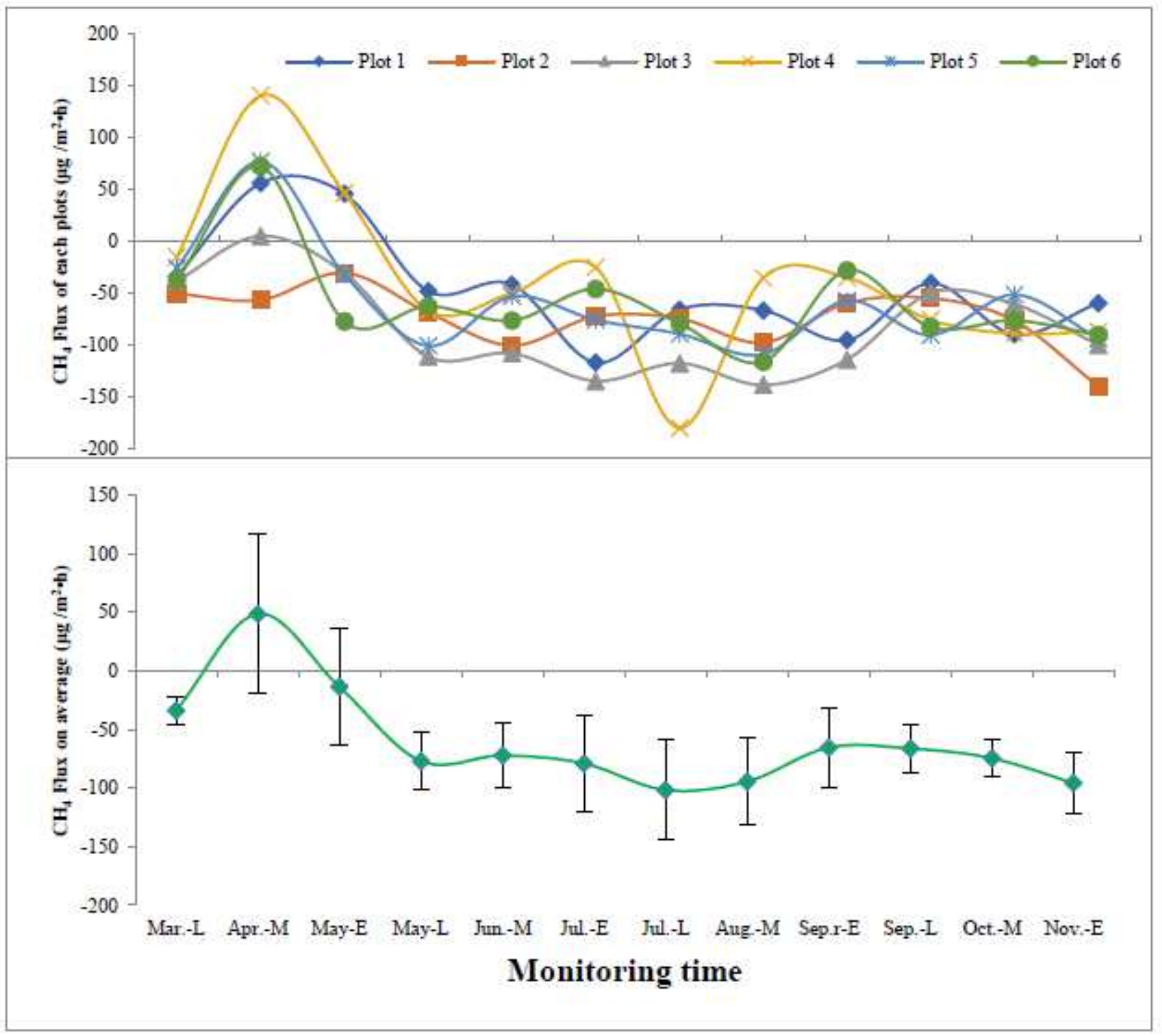

Figure 5

Dynamic process of $\mathrm{CH} 4$ flux rate in different seasons 